\title{
Atmospherics and the Establishment of Long- Term Customer Relationships in a Retail Environment
}

\section{Olivier and $M$ Fletcher}

Department of Marketing and Communication Management, University of Pretoria

\section{ABSTRACT}

With the current focus on establishing long-term customer relationships, the enhancement of the entire shopping experience and the role of atmosphere and the emotional reactions it elicits, are becoming increasingly important. Determining the factors that contribute to the creation of pleasant or unpleasant shopping experiences can influence future strategic planning. The focus of this study falls on the way that the physical environmental factors of a store, more specifically the environmental odour, affect consumers' emotional responses. This is discussed on the basis of environmental psychology, using certain research findings as well as theoretical models to shed more light on this topic.

JEL M49

\section{INTRODUCTION}

Managers of retail and service outlets realise nowadays that the store environment has a significant effect on sales (Milliman, 1982 and 1986; Smith and Curnow, 1966; Stanley and Sewall, 1976), product evaluation (Bitner, 1986; Rappoport, 1982; Wheatley and Chiu, 1977), and consumer satisfaction (Bitner, 1990; Harrel, Hutt, and Anderson, 1980). Often the customer's attitude towards the store environment plays a greater role in the choice of a store than the customer's attitude towards the trade goods themselves (Darden, Erdem and Darden, 1983).

Atmospherics comprises the endeavour to manipulate the retail environment to elicit specific emotional reactions from consumers (Kotler, 1974). This refers to the design of the environment through visual communication, lighting, colours, music and smell, which influence clients' perceptual and emotional responses and, in tum, their purchasing behaviour. 
Most decisions to buy are based on emotions. Of all human senses, the sense of smell bas the greatest impact on emotion (Levy and Weitz, 1998). However the smell of the store environment is a field seldom researched in the study of the retail environment. Speciality stores such as bakeries, coffee shops and tobacconists have for some time trusted in their aroma to attract consumers and in this way induce them to buy more (Bone and Ellen, 1994). These days, however, some service providers and store managers have stores with diverse product lines or product lines with no particular odour, who employ aroma consultants to develop customised fragrances for the store (Miller, 1993). An example of such a company is ATMOSPHERICS - the first US environmental aroma company whose founder was Paul Roche. If a consumer walks into the premises of a Thomas Pink shirtmaker, the gentle fragrance of newly laundered, starched linen greets him or her. "Line-dried linen" is one of the corporate aromas that ATMOSPHERICS has developed for businesses over the past five years.

\section{ATMOSPHERICS: THE IMPACT OF THE PHYSICAL ENVIRONMENT}

Atmospherics or in other words, the physical design and decor elements of a particular environment, have an effect not only on clients but also on employees in the retail and organisational context (Bitner, 1992).

\section{Impact on employees}

The work environment has an influence on employees' satisfaction, productivity and motivation (e.g. Becker, 1981; Davis, 1984; Steele, 1986; Sundstrom and Altman, 1989; Sundstrom and Sundstrom, 1986; Wineman, 1986). How much influence the physical environment will have, however depends on the nature of the employee's position. Odour may improve the work practices of employees. Peppermint, vanilla and apple scents may help to counteract tension while a hint of lemon could offset drowsiness which in turn would lead to fewer errors, especially in the case of fairly boring work (Director, 1997),

\section{Impact on clients}

Research on consumer behaviour has traditionally revealed the strong influence of cognitive psychology. The focus has been on the traditional informationprocessing paradigm, and in using this to explain consumers' decision-making processes and the outcome of their decisions (Bettman, 1979). It was thus found that the observed store environment could indeed elicit cognitive responses, that might influence clients' opinions about a place and the people and products encountered there. Therefore, environment can serve as a form of non-verbal communication (Broadbent, Bunks and Jencks, 1980; Rappoport, 1982). 
The observed store environment also elicits emotional responses which influence consumer behaviour. An individual's mood may affect his or her behaviour without interfering with other cognitive processes (Clark, 1982; Clark and Isen, 1982). In an investigation into people's emotional responses to environment, Mehrabian, Russel and their colleagues found that these responses could be classified into two categories, namely pleasure-non-pleasure (affect) and degree of excitation or arousal. The principles of affect and excitation are elements of environmental psychology. Affect is defined as a general descriptor of a positive or negative state of emotion or feeling (Spangenberg, Crowley and Henderson, 1996). Therefore the most common theoretical basis for the study of the effect of odour, more specifically on the shopping environment, also derives from the field of environmental psychology.

\section{ENVIRONMENTAL PSYCHOLOGY}

Veitch and Arkkelin (1995) define environmental psychology as a multidisciplinary behavioural science, both basic and applied in orientation, whose focus areas are the systematic interrelationship between the physical and social environments as well as individual human behaviour and experience.

Environmental psychology endorses the stimulus-organism-response [S-O-R] paradigm, which states that the environment is a stimulus[S] with clues that jointly affect one's internal evaluation[O], which in turn causes approach/avoidance responses[R]. Thus the characteristics of an environment jointly determine the degree of pleasure/affect or excitation in the observer. Affect describes the positive or negative emotional status of a person. Excitation or arousal is a psychological condition which can be determined directly through verbal reporting. According to environmental psychology, one of the constructs of excitation is load. A high-load pleasant or unpleasant environment will lead to approach or avoidance behaviour, but an environment with a low loading is not activatory enough to motivate any measurable behaviour.

In a study by Sherman, Mathur and Smith (1997), the authors attempted to reinterpret the conceptualisation of store atmosphere, client emotions and purchasing behaviour in terms of stimulus-organism-response in a way consistent with the approach taken in environmental psychology. To this end, they used a causal model which can be briefly described as follows below. 


\section{The Model: Stimulus-Organism-Response}

- Stimulus: In the model, the stimulus is the store atmosphere, as it affects the mood of the consumer. Baker (1986) divides the elements of the store environment into three categories: social factors, design factors and environmental ("ambient") factors. "Ambient" factors are the focus of interest in this study, and they comprise the non-visual elements of the store environment, such as odour and lighting.

- Organism: This refers here to the internal processes that intervene between the stimulus and final behaviour, and consists of perceptual, psychological, emotional and cognitive activities. It is expected that the elements of the store atmosphere will have a positive influence on the components of the consumer's emotional state (affect and excitation).

- Response: This is the consumer's final response or reaction, and includes psychological reactions such as attitudes as well as behavioural responses. Consumers who are in a good mood continuously display higher approach responses, whereas those who reveal more negative affect in their behaviour display greater avoidance (Donovan and Rossiter, 1982).

\section{Figure 1 SOR model of retail purchasing behaviour}

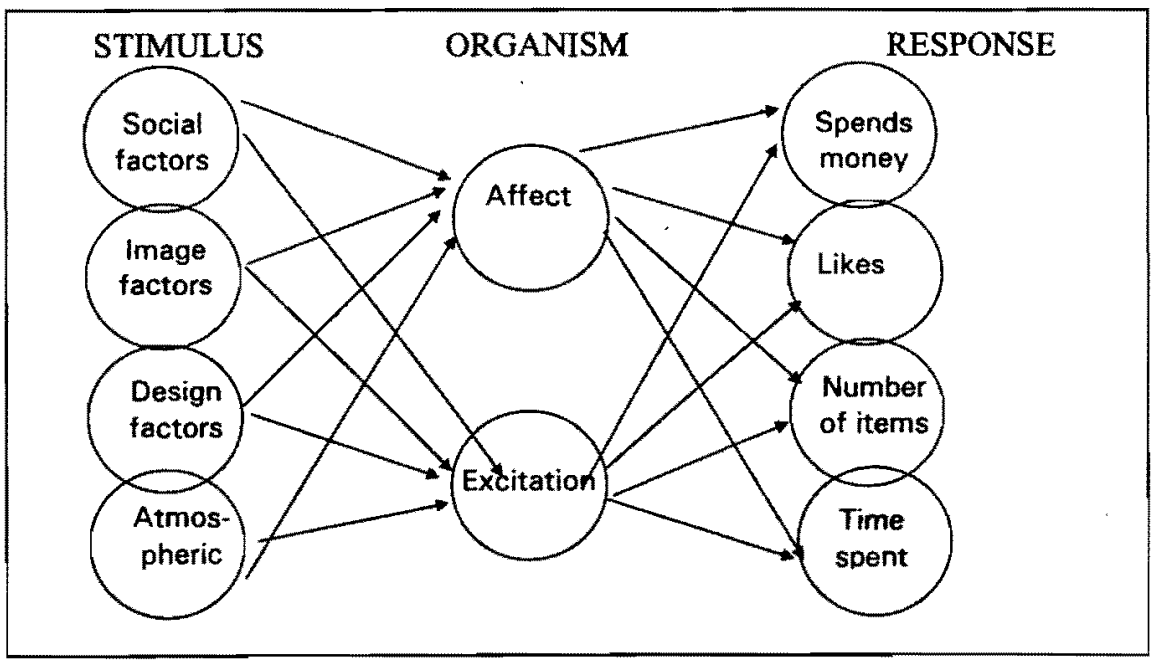

Source: Sherman, E.; Mathur, A. and Smith, R.B. (1997). "Store Environment and Consumer Purchase Behavior: Mediating Role of Consumer Emotions", Psychology \& Marketing, 14(4): 361-378. 
Approach responses include all positive behaviour which can be oriented to a specific place, for example (Donovan and Rossiter, 1982):

- Enjoyment of shopping and the store environment

- Returning (to the store)

- Attraction to and friendliness towards others

- Spending money

- Time spent in the store ("browsing")

- Exploring the store

Avoidance responses reflect the opposite, in other words, a desire not to linger, not to explore, work or associate.

Conceptual and empirical studies support the notion that there is a systematic covariance between the store environment and consumers' affective behaviour (Gardner, 1985; Darden and Babin, 1994). Consumers who are in a good mood continuously reveal greater approach responses; by contrast, those who experience a negative affective reaction display more avoidance responses. Retailers' interests should however extend further than purchases. With the increasing emphasis being placed on building up relationships and retaining existing clients, satisfaction with the retailer is an extremely important consideration because it determines future behaviour. Hence the next theme concerns consumer satisfaction and expenditure.

\section{INFLUENCE OF CUNSUMER MOOD ON EXPENDITURE AND SATISFACTION}

Several rationales support a relationship between positive emotions and purchasing. Firstly, people who are in a positive mood have a greater tendency to reach a decision (Isen, 1989). Experiments indicate that subjects who report a positive mood take less time to make consumer decisions. Visitors to shopping centres, who had experimentally induced positive moods, tended to make a greater number of purchases than those whose mood had not been altered (Isen, 1987).

Moreover, there is an intuitive rationale surrounding reciprocal treatment. If the buyers' mood is improved by visiting a shopping environment, they might wish to reciprocate the favour by purchasing something. Similarly, people who are in a bad mood when visiting a store might not wish to reward the retailer by doing any business there.

The study by Babin and Darden (1996) used a measure that included actual expenditure behaviour as well as supporting a direct association between consumers' shopping mood and satisfaction. They found a significant positive 
relationship between positive mood and purchasing behaviour. It was determined that a unit increase in the positive mood of a consumer could lead to a 12 per cent increase in expenditure. But an increase in a negative mood did not lead to a noteworthy decrease in expenditure.

The study also suggests that a negative mood among shoppers, even though it does not affect expenditure, does diminish satisfaction significantly more than a positive mood enhances satisfaction. Figure 2 summarises the implications for patronage behaviour.

\section{Figure 2 Expected outcomes of changes in consumers' mood}

\begin{tabular}{|l|l|l|}
\hline \multirow{2}{*}{ Increments in positive mood } & \multicolumn{2}{c|}{ Expenditure } \\
\cline { 2 - 4 } Increments in negative mood & are associated with \\
increased expenditure & $\begin{array}{l}\text { Save associated with } \\
\text { high satisfaction }\end{array}$ \\
\cline { 2 - 3 } & have little effect & $\begin{array}{l}\text { have the greatest } \\
\text { impact on satisfaction }\end{array}$ \\
\hline
\end{tabular}

Source: Babin, B.J. and Darden, W.R. (1996). "Good and Bad Shopping Vibes: Spending and Patronage Satisfaction", Journal of Business Research, 35: 201-6.

Retailers who make substantial investments in the physical environment of the store, in an effort to improve consumers' moods and avoid negative moods, should feel encouraged by these findings. Although positive moods do increase expenditure to some extent, the real reward is the greater consumer satisfaction that these moods engender.

This research appears to indicate that environmental factors really do influence the consumer in various ways. Since odour is one of the most easily manipulated and most common of factors, a background to this instrument of atmospherics is next considered.

\section{SMELL AS AN INSTRUMENT OF ATMOSPHERICS}

Retailers should carefully plan the odours that they use, according to the composition of their target market. The following background about this instrument may provide some insight into this. 


\section{Dimensions of smell}

Most research distinguishes between odours on the basis of three different but not necessarily independent dimensions, namely:

(1) affective quality of the odour (how pleasant it is);

(2) nature of excitation (how likely it is to elicit a psychological response); and

(3) intensity (how strong it is).

The affective dimension of odour dominates perceptions of smell in existing research (Engen, 1982; Moskowitz, 1979; Schiffman, 1979; Woskow, 1968). This is understandable because smell is processed in the limbic system of the brain, which is the centre of emotion (Leukel, 1976; Restak, 1984). The arousal dimension of smell has been proved by the effect of odours on both EEG (electroencephalogram) and respiratory patterns (Lorig and Schwarz, 1988; Schwarz et al., 1986). The intensity dimension of odours has a negative association with evaluations of odours, meaning that as an odour becomes stronger, reactions to it become increasingly negative (Doty et al., 1978; Henion, 1971; Richardson and Zucco, 1989). This is generally valid for all odours. However, it is suggested that the relation between the intensity of the odour and the affective reactions depends on how pleasant the odour is. Every stimulus has an optimum level of preference (Spangenberg, Crowley and Henderson, 1996).

Research by Mathur and Smith (1997) indicates that the pleasantness of the store has a positive effect on the amount of money customers spend in that store, and on how much they like the store. The excitation element has a positive impact on the amount of money spent in the store, the time spent there and the number of items bought in the store.

\section{Effect of smell}

Most of the research on the effect of smell focuses on reactions to nonatmospheric smells, in other words localised smells - for example in a flask or on a card, on a person, a product or an advertisement. It was found that evaluations of people and objects are more positive when they are scented. There is also a more positive relation when the aroma and the product are congruent (Bone and Jantrania, 1992).

The effect of environmental odour in the marketing environment is a subject on which very few studies have been done so far. Two studies on the effect of environmental odour on product choice have produced useful findings. In one study, participants undertook a catalogue shopping task in scented and unscented rooms. It was found that the participants spent more time on the task 
in the presence of a pleasant environmental odour that without it (Bone and Ellen, 1994). In the other study a computer-aided experiment on product choice was done in differently scented rooms. In that experiment, the correspondence of odour and product category did influence various information-processing measures (Mitchel, Kahn and Knaso, 1995).

\section{The influence of environmental smell on perception of time}

Spangenberg, Crowley and Henderson (1996) shed some light on the subject in a study which noted the use of non-repulsive odour versus no odour, and the effect of these elements on approach/avoidance behaviour in a retail environment. It was found that the participants who were exposed to the scented environment perceived that they had spent less time in the store than did the people in the unscented environment. The participants who were exposed to the no-odour conditions furthermore thought that they had spent far more time in the store than they actually had. These findings suggest that environmental odour may lead to improved subjective experiences on the part of retail clients. The time that consumers spend in investigating trade goods, waiting in queues and for assistance, could be subjectively shortened by using environmental odour in the store environment.

\section{CONCLUSION}

The findings discussed in this paper provide guidelines and opportunity for managers of retailer stores to utilise the advantages of scenting the environment with pleasant or neutral odours. The message is clear: the presence of a pleasant aroma in a store is a relatively inexpensive and an effective way of improving consumers' reactions to the store and its trade goods. In addition the aroma encourages a positive feeling and satisfaction which help to establish long-term consumer relationships.

\section{REFERENCES}

1 BABIN, B.J. and DARDEN, W.R. (1996) "Good and Bad Shopping Vibes: Spending and Patronage Satisfaction", Journal of Business Research, 35: 201-6.

2 BABN, B.J.; DARDEN, W.R. and BABIN, L.A. (1996) "Positive and Negative Consumer Emotions: Affect or Artifact", Journal of Business Research. 
3 BAKER, J. (1986) "The Role of Environment in Marketing Services: the Consumer Perspective", The Services Challenge: Integrating for Competitive Advantage, 79-84.

4 BITNER, M.J. (1992) "Servicescapes: The Impact of Physical Surroundings on Customers and Employees", Journal of Marketing. 56(April): 57-71.

5 BONE, P.F. and SWATI, J. (1992) "Olfaction as a Cue for Product Quality", Marketing Letters, 3(July): 289-96.

6 DARDEN, W.R. and BABIN, B.J. (1994) "Exploring the Concept of Affective Quality: Expanding the Concept of Retail Personality", Journal of Business Research, 29(February): 101-10.

7 DONOVAN, R. and ROSSITER, J. (1982) "Store Atmosphere: an Environmental Psychology Approach", Journal of Retailing, 58(Spring): 34-57

8 DOTY, R.L.; ORNDORFF, M.M.; LEYDEN, J. and KLIGMAN, A. (1978) "Communication of Gender from Human Auxillary Odors: Relationship to Perceived Intensity and Hedonicity", Behavioral and Neural Biology, 23(July): 373-80.

9 ENGEN, T. (1982) The Perception of Odors, New York: Academic Press.

10 GARDNER, M.P. (1985) "Mood States and Consumer Behaviour: a Critical Review", Journal of Consumer Research. 12(December): 218300.

11 HENION, K.E. (1971) "Odor Pleasantmess and Intensity; a Single Dimension", Journal of Experimental Psychology, 90(2): 275-9.

12 ISEN, A.M. (1987) "Positive Affect, Cognitive Processes, and Social Behavior", Advances in Experimental Social Psychology, 203-51.

13 KIRK-SMITH, M.D. and BOOTH, D.A. (1987) "Chemoreception in Human Behavior: Experimental Analysis of the Social Effects of Fragrances", Chemical Senses, 12(1): 159-66.

14 LEUKEL, F. (1976) Introduction to Physiological Psychology, St. Louis, MO: C.v. Mosby

15 LEVIN, J.M. and MCBURNEY, D.H. (1986) "The Role of Olfaction in Social Perception and Behavior", Physical Appearance Stigma, and Social Behavior: the Ontario Symposium, 3: 179-217.

16 LEVY and WEITZ (1998) Retailing Management (3rd ed.) McGrawHill Companies Inc. :USA

17 LORIG, T.S. and SCHWARTZ, G.E. (1988) "Brain and Odor: I. Alteration of Human EEG by Odor Administration", Psychobiology. 16(3): 281-4.

18 MITCHELL, D.J.; KAHN, B.E. and KNASKO, S.C. (1995) "There's Something in the Air: Effects of Ambient Odor on Consumer Decision Making", Journal of Consumer Research, 22(September): 229-38. 
19 MOSKOWITZ, H.R. (1979) "Mind, Body, and Pleasure: An Analysis of Factors which Influence Sensory Hedonics", Preference Behaviour and Chemoreception: 131-47.

20 RESTAK, R. (1984) The Brain, Toronto: Bantam Books

21 RICHARDSON, J.T.E. and GESUALDO, M.Z. (1989) "Cognition and Olfaction: A Review", Psychological Bulletin, 105(3): 352-60.

22 SCHIFFMAN, S.S. (1979) "Preference: A Multidimensional Concept", Preference Behaviour and Chemoreceptio: 63-81.

23 SHERMAN, E; MATHUR, A. and SMITH, R.B. (1997) "Store Environment and Consumer Purchase Behavior: Mediating Role of Consumer Emotions", Psychology \& Marketing, 14(4): 361-78.

24 SPANGENBERG, E.R.; CROWLEY, A.E. and HENDERSON, P.W. (1996) "Improving the Store Environment: Do Olfactory Cues Affect Evaluations and Behaviors?", Journal of Marketing, 60(April): 67-80.

25 WOSKOW, M.H. (1968) "Multidimensional Scaling of Odors," in Theories of Odors and Odor Measurement, N. Tanyolac, (ed.) Bebek, Istanbul: Robert College Research Center: 147-91. 